\title{
Quality indicators for hip and knee osteoarthritis management in New Zealand: A patient survey
}

Peter J. Larmer DHSC

Head of School, School of Clinical Sciences, Auckland University of Technology, Auckland, New Zealand

Katie Bennett BHSC (Physiotherapy)

Physiotherapist, Auckland District Health Board, Auckland, New Zealand

Jennifer N. Baldwin $P h D$

School of Clinical Sciences, Auckland University of Technology, Auckland, New Zealand. School of Health Sciences, Faculty of Health and Medicine, University of Newcastle, Callaghan, Australia

Sandra Bassett $P h D$

School of Clinical Sciences, Auckland University of Technology, Auckland, New Zealand

Daniel W. O'Brien $P h D$

Senior Lecturer, Physiotherapy Department, School of Clinical Sciences, Auckland University of Technology, Auckland, New Zealand

ABSTRACT

Osteoarthritis is a prevalent and costly condition. Knowledge of the quality of care being offered to people with hip and knee osteoarthritis in New Zealand is limited. The aim of this study was to investigate the quality of care being offered to people with hip and knee osteoarthritis in New Zealand, and to investigate common pathways of care. The OsteoArthritis Quality Indicator (osteoarthritis) questionnaire was administered to adults with hip and/or knee osteoarthritis, and participants were also asked to list the healthcare professionals they had consulted. Descriptive statistics with 95\% confidence intervals were calculated. The study included 106 participants (87\% female, $n=92 ; 94 \%$ European, $n=100)$. The mean OsteoArthritis Quality Indicator achievement rate was 50.2\% (95\% confidence intervals 41.0-59.7\%). OsteoArthritis Quality Indicator achievement rates were lowest for weight reduction referral $(8.6 \% ; 3.7-17.8 \%)$ and daily activity aids assessment $(18.5 \% ; 10.2-31.0 \%)$, and highest for physical activity education $(80.8 \% ; 72.1-87.3 \%)$ and offering of paracetamol $(80.0 \% ; 71.3-86.6 \%)$. Following consultation with a general practitioner, $22 \%(n=24)$ consulted orthopaedic surgeons while $15 \%(n=17)$ consulted physiotherapists. The results suggest that implementation of evidence-informed conservative treatments for osteoarthritis in primary care is suboptimal, although evidence from a larger representative sample is needed.

Larmer, P. J., Bennett, K., Baldwin, J. N., Bassett, S., \& O’Brien, D. W. (2019). Quality indicators for hip and knee osteoarthritis management in New Zealand: A patient survey. New Zealand Journal of Physiotherapy, 47(3), $183-192$. https://doi.org/10.15619/NZJP/47.3.06

Key Words: Osteoarthritis, New Zealand, Treatment, Hip, Knee

\section{INTRODUCTION}

Osteoarthritis (OA) of the hip and knee is currently ranked the eleventh highest contributor to disability globally (Cross et al., 2014). People with OA often experience pain, joint stiffness and weakness, which can affect their mobility, function, mental well-being and independence (Hall et al., 2008; Hermans et al., 2012). The prevalence of OA in New Zealand has increased from $9 \%$ of adults in $2011 / 2012$ to $10.6 \%$ in $2017 / 2018$ and is expected to continue rising with the ageing population, which will increase the burden and reliance on healthcare resources (Baldwin, Briggs, Bagg, \& Larmer, 2017; Hooper, Lee, Rothwell, \& Frampton, 2014; Ministry of Health, 2019). In 2018, the estimated total cost of arthritis in New Zealand, of which OA is the most common form, was $\$ 12.2$ billion dollars (Access Economics, 2018). Hospital costs, which are dominated by osteoarthritic knee and hip surgeries, totalled $\$ 423.7$ million (Access Economics, 2018).

International evidence-based OA treatment guidelines commonly place interventions into three categories: nonpharmacological, pharmacological or surgical (Department of Veterans Affairs, \& Department of Defense, 2014; Jevsevar et al., 2013; National Institute for Health and Care Excellence, 2015; Rillo et al., 2016; Zhang et al., 2008). These guidelines suggest that interventions be staged and progress from conservative non-pharmacological interventions, such as education and exercise, to more invasive interventions, such as surgery (Brosseau et al., 2016; Department of Veterans Affairs, \& Department of Defense, 2014; Hochberg et al., 2012; Loew et al., 2012; National Institute for Health and Care Excellence, 2015; Zhang et al., 2008). Furthermore, surgical intervention should only be recommended for those people who have failed to respond to non-pharmacological and pharmacological treatments, and whose quality of life is acutely impacted (Department of Veterans Affairs, \& Department of Defense, 2014; National Institute for Health and Care Excellence, 2015; Zhang et al., 2008). However, evidence from Australia and France demonstrates implementation of these guidelines 
into clinical practice is limited and that non-pharmacological treatments are commonly underutilised (Brand et al., 2014; Chevalier, Marre, de Butler, \& Hercek, 2004; Hunter, 2011; Hunter \& Lo, 2009; Poitras et al., 2010). In New Zealand, many people with OA who are referred for joint replacement surgery are either not appropriate for surgery or face a lengthy waiting list (Hooper, 2016). This is especially problematic given that the number of New Zealanders who will require a total hip or knee joint replacement is expected to rise by $84 \%$ and $183 \%$ respectively by 2026 (Hooper et al., 2014).

The OsteoArthritis Quality Indicator (OA-QI) questionnaire is a patient-reported outcome measure that investigates the quality of care, in terms of adherence to clinical guidelines, being offered to people with OA (Østerås et al., 2013). The questionnaire is in English and consists of 17 items ("quality indicators"), 16 of which address patient education, exercise, weight loss, and mobility interventions and pharmacological management or non-surgical interventions that are supported by international clinical guidelines (Østerås et al., 2013). The OA-QI questionnaire has demonstrated acceptable content validity, construct validity, and test-retest reliability in a Norwegian sample of people with hip, knee, and hand OA (Grønhaug, Hagfors, Borch, Østerås, \& Hagen, 2015; Grønhaug, Østerås, \& Hagen, 2014; Østerås et al., 2015; Østerås et al., 2013) .

A recent qualitative study that explored treatments offered to New Zealanders $(n=23)$ with lower limb OA found that the first clinician most commonly consulted by participants was a general practitioner (GP) (Jolly, Bassett, O’Brien, Parkinson, \& Larmer, 2017). Participants indicated that they were not aware of a distinct treatment pathway for their OA, and many reported receiving inconsistent information from different healthcare providers, although the findings of the study are difficult to generalise because of the qualitative methodology. There is limited knowledge of the quality of care being offered to people with hip and knee OA in New Zealand and whether the care being offered is in line with international clinical guidelines. Therefore, this study had two aims, to:

1. Investigate the quality of care being offered for people with hip and knee OA in New Zealand compared to international guidelines.

2. Investigate clinical pathways of OA management in New Zealand in terms of healthcare professionals consulted.

\section{METHODS}

A cross-sectional observational study involving administration of an online survey at a single time point was conducted. Ethical approval was granted by the Auckland University of Technology Ethics Committee (reference number 16/407).

\section{Participants}

People were eligible to participate in the study if they were aged 18 years or older, had been diagnosed with hip and/or knee OA by their GP and had received treatment for it, and if they could comprehend written English. Participants were recruited via social media (Facebook), Arthritis New Zealand newsletters ( $n=$ approximately 2,800 subscribers at time of study), flyers placed on community noticeboards as well as through snowballing techniques. The advertisements included a link to the online survey. People who chose to follow the link to the survey were first directed to the participant information sheet and the informed consent question, and those who consented to participate were next directed to the survey. Participants could choose to stop answering the questionnaire at any point or skip a question within the survey. The questionnaire was administered through SurveyMonkey (SurveyMonkey Inc., San Mateo, California, United States) and was available online between December 2016 and May 2017.

\section{Data collection}

The questionnaire consisted of three sections (see Appendix A). The first section collected data regarding sociodemographic characteristics: age, gender, ethnicity, occupational status, education, physical activity level, comorbidities, and any medications or supplements that participants were taking at the time of survey completion. Ethnicity was self-reported and re-coded to the following ethnic groups used by the Ministry of Health: European, Māori, Pacific Island, Asian or Middle Eastern/ Latin American/African (Ministry of Health, 2010). Ethnicity was coded using the hierarchical method, in which each individual was assigned one ethnic group using a priority order, with Māori prioritised first followed by Pacific, Asian, Middle Eastern/Latin American/African and European/Other (Statistics New Zealand, 2013).

The second section collected data regarding participants' OA characteristics: hip and/or knee joint/s affected, duration of symptoms, time since diagnosis and average pain intensity in the past week (rated on a numerical rating scale from 0-10 where 0 is no pain and 10 is the worst pain imaginable). Participants were also asked to list in chronological order all healthcare professionals they had consulted for their OA.

\section{OA-QI questionnaire}

The third section of the survey consisted of the 17-item OAQI questionnaire (Østerås et al., 2013). Individual items in the survey each referred to a specific intervention for OA recommended by international clinical guidelines (e.g. the National Institute for Health and Clinical Excellence [NICE] guidelines) (National Institute for Health and Care Excellence, 2015). Participants were asked to respond "Yes", "No", or "Not applicable" indicating whether they had been offered that intervention. Six items related to education regarding OA: disease progression, treatment alternatives, self-management, lifestyle change and physical activity. Two items asked participants about weight-loss interventions, three items about mobility interventions, and five items about pharmacological management (including offering paracetamol, stronger pain killers, and non-steroidal anti-inflammatory drugs [NSAIDs]). The final item asked whether participants have been referred for surgical assessment. An additional question was included in this study asking participants whether they had undergone surgery for their OA. Minor wording changes were made to the OA-QI for the New Zealand context, e.g. the drug name acetaminophen was replaced with paracetamol.

\section{Data analysis}

Data were analysed using SPSS Windows 22.0 software package (IBM SPSS Inc, Chicago, IL, United States). Continuous data were analysed as means, standard deviations, and ranges. Categorical 
data were analysed using frequencies and percentages of total responses. OA-QI achievement rates were calculated for each individual quality indicator and for the study sample as a whole, whereby the numerator represented the number of "Yes" responses and the denominator represented the number of eligible responses (that is, the total number of "Yes" and "No" responses) (Østerås et al., 2013). Confidence intervals were calculated using the Adjusted Wald Method (2005).

\section{RESULTS}

A total of 118 people were recruited to the study, of which five participants completed informed consent but did not continue with the questionnaire, and a further seven partially completed the survey. Hence, analysis was undertaken on 106 complete surveys.

\section{Table 1: Demographic and osteoarthritis characteristics of participants $(n=106)$}

\begin{tabular}{|c|c|c|}
\hline Characteristic & & $n(\%)^{\text {a }}$ \\
\hline Age (years) & Mean (SD), range & $62.4(11.9), 18-86$ \\
\hline \multirow[t]{2}{*}{ Sex } & Female & $92(87)$ \\
\hline & Male & $14(13)$ \\
\hline \multirow[t]{5}{*}{ Ethnicity } & Māori & $3(3)$ \\
\hline & Pacific Islander & 0 \\
\hline & Asian & $2(2)$ \\
\hline & Middle Eastern/Latin American/African & $1(1)$ \\
\hline & European & $100(94)$ \\
\hline \multirow[t]{3}{*}{ Occupational status } & Working full time/part time & $55(52)$ \\
\hline & Retired & $42(40)$ \\
\hline & Unemployed/student/disability beneficiary & $9(8)$ \\
\hline \multirow[t]{2}{*}{ Highest education level } & Secondary & $27(26)$ \\
\hline & Tertiary & $79(75)$ \\
\hline \multirow[t]{5}{*}{ Physical activity level } & Never & $1(1)$ \\
\hline & Less than once a week & $6(6)$ \\
\hline & Once a week & $11(10)$ \\
\hline & 2-3 times per week & $35(33)$ \\
\hline & Almost every day & $53(50)$ \\
\hline \multirow[t]{2}{*}{ Comorbidities } & Other rheumatic diseases & $14(13)$ \\
\hline & Other chronic non-rheumatic diseases & $30(28)$ \\
\hline \multirow[t]{2}{*}{ OA site } & Hip & $67(63)$ \\
\hline & Knee & $80(75)$ \\
\hline Pain or stiffness in the last month & Yes & $104(98)$ \\
\hline \multirow[t]{2}{*}{ Time since OA symptom onset } & $<5$ years & $33(31)$ \\
\hline & $5-10$ years & $31(29)$ \\
\hline
\end{tabular}

Demographic and disease characteristics

The mean (standard deviation [SD]) age of participants was $62.4(11.9)$ years. The majority of participants were female $(87 \%, n=92)$ and of European ethnicity $(94 \%, n=100)$ (Table 1). Approximately half were employed $(52 \%, n=55)$, three-quarters had attained tertiary qualifications $(75 \%, n=79)$ and half reported engaging in physical activity almost every day (50\%, $n=53)$. Over three-quarters $(75 \%, n=80)$ reported knee OA while $63 \%(n=67)$ reported hip OA. Almost all participants had experienced pain or stiffness in the past month $(98 \%, n=104)$ with a mean (SD) pain intensity of 5.5 (2.1) out of 10. 


\begin{tabular}{lll}
\hline Characteristic & $>10$ years & $n(\%)^{\text {a }}$ \\
\hline Time since OA diagnosis & $<5$ years & $42(40)$ \\
& $5-10$ years & $51(48)$ \\
& $>10$ years & $27(25)$ \\
Pain level, mean (SD) ${ }^{b}$ & Not reported & $23(22)$ \\
\hline
\end{tabular}

Note: OA, osteoarthritis; SD, standard deviation

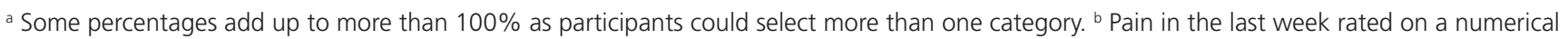
rating scale from 0 (no pain) to 10 (worst pain imaginable).

OA quality indicator achievement rates

Achievement rates were calculated for each OA quality indicator, representing the proportion of participants in the sample who had reported receiving that intervention during the course of their OA management. There was wide variation in achievement rates across the $17 \mathrm{OA}$ quality indicators. The average achievement rate for OA quality indicators was 50.2\% (95\% Cl 41.0-59.7\%) (Figure 1). Achievement rates were lowest for weight reduction referral $(8.6 \% ; 3.7-17.8 \%)$, daily activity aids assessment $(18.5 \% ; 10.2-31.0 \%)$, daily activity functional assessment (27.7\%; 19.2-38.2\%) and walking aid assessment
(30.3\%; 20.5-42.3\%). Achievement rates were highest for physical activity education $(80.8 \% ; 72.1-87.3 \%)$, offering of paracetamol for pain relief $(80.0 \% ; 71.3-86.6 \%)$, offering of NSAIDs $(72.0 \% ; 62.5-79.9 \%)$, and referral for surgical assessment (65.4\%; 54.6-74.9\%).

Eligible responses exclude those stating not applicable/do not remember and those who did not respond. Overall pass rate calculated as mean $(95 \% \mathrm{Cl})$ of pass rates for all indicators.

Clinical pathway for people with OA

Table 2 shows the clinical pathways followed by participants

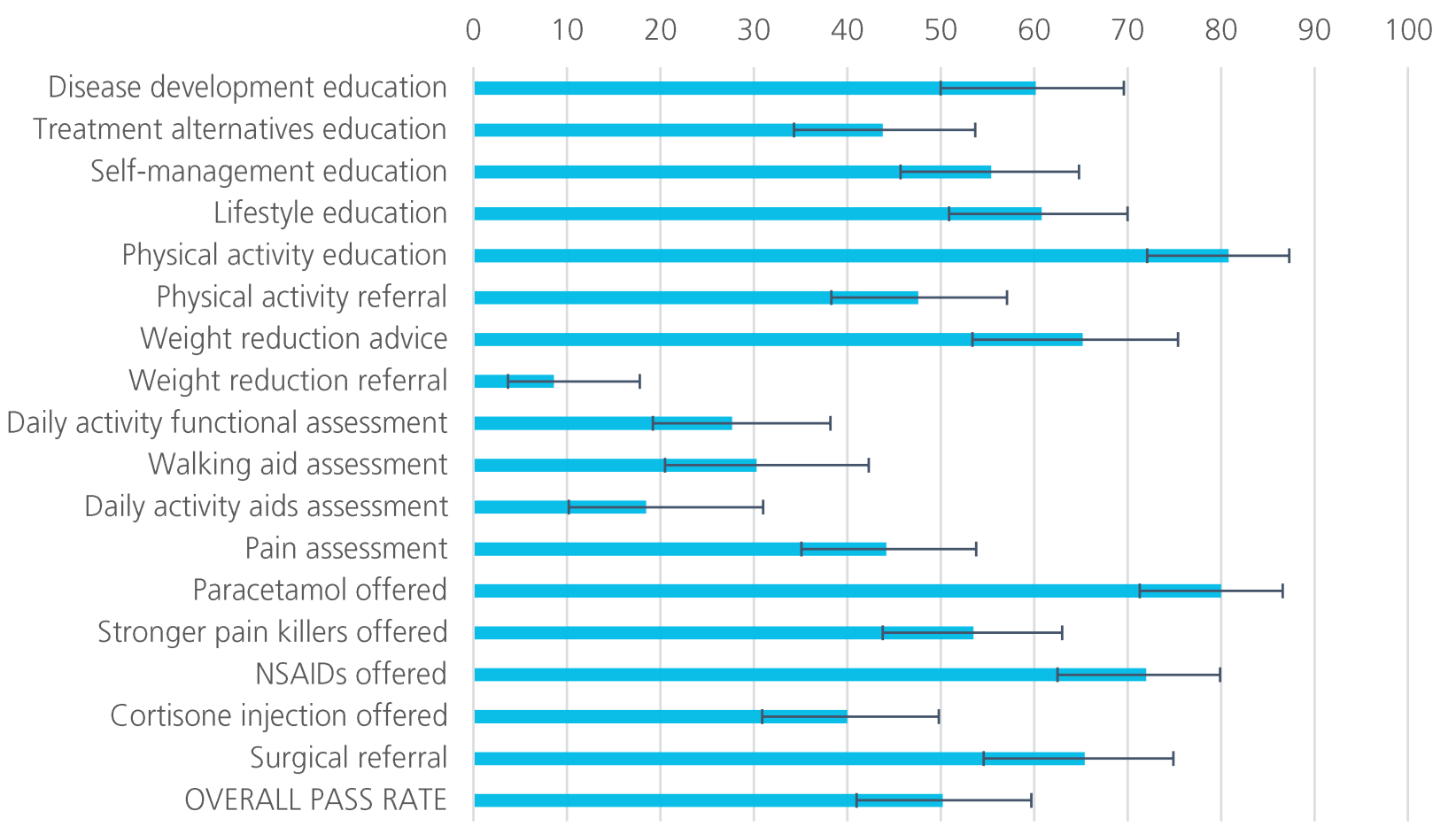

Note: $\mathrm{Cl}$, confidence interval; OA, osteoarthritis

Figure 1: Achievement rates for OA quality indicators, represented as percentage $(95 \% \mathrm{Cl})$ of eligible respondents 
in terms of the chronological order in which they consulted with healthcare professionals. The GP was the first professional consulted for $92.4 \%(n=98)$ of participants. Almost one-third $(30.0 \%, n=24)$ of participants saw an orthopaedic surgeon as their second healthcare professional, while $21.3 \%(n=17)$ saw a physiotherapist and $13.8 \%(n=11)$ saw another health professional.

\section{DISCUSSION}

This study aimed to investigate the quality of care being offered to people with hip and knee OA in New Zealand using a validated patient-reported outcome measure - the OAQI (Østerås et al., 2013). On average, half of the 17 clinical indicators were met, although there was wide variation in achievement rates. Physical activity education, pharmacological management and surgical referral represented areas of strength in quality of care, while weight reduction and daily activity assessment were identified as areas for improvement. While almost all participants reported consulting their GP for their $\mathrm{OA}$, there was a great deal of variation in subsequent clinical pathways in terms of other clinicians consulted. Generalisation of these findings to the broader population of New Zealanders with $\mathrm{OA}$ is limited on account of the small, non-representative sample.

\section{Strengths and limitations}

The two primary strengths of this study were that it collected data about treatments from the patient's perspective and that it employed a validated patient-reported outcome measure, which allowed direct comparison of the findings with previous research conducted elsewhere. The study had four important limitations. Firstly, the small sample size and lack of heterogeneity limits generalisability of the findings. Specifically, our sample comprised mostly females (87\%), and had a higher proportion of participants of European ethnicity (94\% compared to 74\% in the national population) and participants reporting tertiary qualifications (75\% compared to $51 \%$ of New Zealanders), although self-reported physical activity rates were comparable (50\% reported engaging in physical activity almost every day compared to $51 \%$ of New Zealanders) (Ministry of Education, 2017; Sport New Zealand, 2015; Statistics New Zealand, 2013). Secondly, the use of self-reported data on treatments received may have introduced bias that may not reflect actual behaviour. Thirdly, the survey was conducted online, eliciting an undefined sample, an unknown response rate and no ability to follow up with non-responders. Fourthly, as we only included people who had been told by their GP that they had OA, our sample did not include people who have OA but have not been diagnosed by a GP. As such, generalisability of these findings to the broader OA population, particularly Māori, Pacific Islanders and other nonEuropean ethnicities, is limited.

\section{OA quality indicator achievement rates}

The mean achievement rate of $50 \%$ for the OA quality indicators was higher than previous studies, which ranged from 31 to 47\% (Grønhaug et al., 2015, 2014; Østerås et al., 2015; Østerås et al., 2013). This difference may be due to discrepancies between the inclusion criteria of the studies, with two including participants with hand, hip and knee OA (Grønhaug et al., 2015; Østerås et al., 2013); and one with knee OA only (Østerås et al., 2015). Nonetheless, the mean achievement rate of $50 \%$ is still less than optimal, as not all treatments outlined in clinical guidelines are being implemented. Encouragingly, over $80 \%$ of participants reported receiving

\section{Table 2: Clinical pathways for people with hip and/or knee osteoarthritis in terms of order of health professionals}

consulted

\begin{tabular}{|c|c|c|c|c|c|}
\hline & \multicolumn{4}{|c|}{$\begin{array}{l}\text { Visit order } \\
\quad n(\%)\end{array}$} & \multirow{2}{*}{$\begin{array}{l}\text { Visited at least } \\
\text { once } \\
n(\%)\end{array}$} \\
\hline & First & Second & Third & Fourth & \\
\hline General practitioner & $98(92)$ & $4(5)$ & $2(4)$ & $1(4)$ & $105(99)$ \\
\hline Orthopaedic surgeon & - & $24(30)$ & $13(28)$ & $4(16)$ & $42(40)$ \\
\hline Physiotherapist & $4(4)$ & $17(21)$ & $8(17)$ & $6(24)$ & $30(28)$ \\
\hline $\begin{array}{l}\text { Medical specialist (e.g. rheumatologist, sports } \\
\text { medicine specialist) }\end{array}$ & - & $9(11)$ & $5(11)$ & $2(8)$ & $15(14)$ \\
\hline Pharmacist & $2(2)$ & $7(9)$ & $3(6)$ & $3(12)$ & $15(14)$ \\
\hline $\begin{array}{l}\text { Other health professional (e.g. chiropractor, } \\
\text { acupuncture, osteopath, laser therapist, massage } \\
\text { therapist, personal trainer) }\end{array}$ & $2(2)$ & $11(14)$ & $11(23)$ & $9(36)$ & $31(29)$ \\
\hline Arthritis educator & - & $8(10)$ & $5(11)$ & - & $13(12)$ \\
\hline
\end{tabular}

Note: Visit order for first four reported health professionals only. For second, third and fourth visits, percentages calculated using the total number of participants in each column as the denominator 
education about physical activity, which is similar to the OAQI achievement rate in previous studies (Grønhaug et al., 2015, 2014; Østerås et al., 2015; Østerås et al., 2013). This is in keeping with clinical guidelines that advocate for the promotion of physical activity for all people with hip and knee OA (Department of Veterans Affairs, \& Department of Defense, 2014; Loew et al., 2012; National Institute for Health and Care Excellence, 2015; Zhang et al., 2008). However, in our study, less than half of participants surveyed had been provided with a referral for physical activity management, supporting the need for improved multi-disciplinary management in New Zealand. The achievement rates for pharmacological interventions (recommended Paracetamol as first medication [80\%] and information about anti-inflammatory side-effects [72\%]) were higher than identified in previous research, suggesting that pharmacological interventions for OA may be more popular in New Zealand than in other countries (Grønhaug et al., 2014; Østerås et al., 2015; Østerås et al., 2013).

The lowest OA-QI achievement rate was for referral to services for losing weight. While $65 \%$ of participants received advice about weight loss, less than one in 10 participants (9\%) were provided with a referral for weight-loss services, a pattern that matches previous research (Grønhaug et al., 2015; Østerås et al., 2015; Østerås et al., 2013). A reduction in body weight of between 5 and $10 \%$ can significantly reduce pain for people with lower limb OA, and as such, current treatment guidelines recommend weight loss for anyone with $\mathrm{OA}$ who is overweight (Brosseau et al., 2016, 2011; Hochberg et al., 2012). However, weight loss is particularly challenging for people with OA when physical activity is limited by joint pain (Bliddal, Leeds, \& Christensen, 2014; Carmona-Terés et al., 2017). As such, providing support for people with OA who are overweight or obese is important. The low achievement rate for referral to weight-loss services in this study could be explained by the limited funding of dietetic services in New Zealand and a lack of support for GPs to provide these referrals.

Clinical pathway for OA

The current study adds to existing evidence indicating that the majority of New Zealanders consult their GP about hip and/or knee OA symptoms, and for most people, the GP is the first health professional consulted (Jolly et al., 2017). The high variation among the types of health professionals subsequently consulted highlights that there is at present no clear clinical pathway for people with OA. The introduction of an OA model of care could help provide a clearer clinical pathway, support linkages between health professionals and improve the uptake of evidence-informed clinical guidelines (Baldwin et al., 2017).

The percentage of participants (40\%) who reported consulting an orthopaedic surgeon seems high, especially as guidelines indicate that conservative treatment options should be exhausted before surgery is considered and many people with OA do not require surgical intervention (Brand et al., 2014; Brosseau et al., 2016; Department of Veterans Affairs, \& Department of Defense, 2014; Hochberg et al., 2012; Loew et al., 2012; National Institute for Health and Care Excellence, 2015; Zhang et al., 2008). This finding may reflect the participants' relatively long mean time since diagnosis (69\% were diagnosed at least five years ago). However, the relatively high rate of referrals may also reflect the absence of a clear clinical pathway for primary care management of OA following best practice guidelines that emphasise conservative treatments.

Less than one-third of all participants reported consulting with a physiotherapist about their OA, which is lower than previously reported (Grønhaug et al., 2014). Exercise therapy and physical activity form part of the core treatments for OA outlined in the NICE clinical guidelines (National Institute for Health and Care Excellence, 2015). In New Zealand, these treatments are often the domain of physiotherapists. There are two possible explanations for the lower than expected rates of physiotherapy consultations: (i) the cost of therapy may have been a barrier, as there is currently limited public funding available in New Zealand for the conservative treatment of people with hip and/or knee $\mathrm{OA}$; and (ii) the participants surveyed reported high habitual physical activity rates (over $80 \%$ undertook physical activity at least twice weekly) and thus might not have felt the need to consult a physiotherapist, although the type of physical activity was not collected.

Nonetheless, NICE clinical guidelines recommend both local muscle strengthening (e.g. comprising specific exercises prescribed by a physiotherapist) as well as general aerobic fitness (National Institue for Health and Care Excellence, 2015), and physiotherapists possess specialist expertise in both of these areas.

\section{CONCLUSION}

On average, quality indicators for OA were achieved for half of this small sample of New Zealanders surveyed with hip and knee OA. Weight reduction referral and daily activity aids assessment were least frequently reported as being treatments received by people with $\mathrm{OA}$, and these represent treatments which lie within the expertise and scope of physiotherapists. While GPs are consulted for the majority of patients with OA, the followup care pathway is varied and inconsistent. Quality improvement for management of OA is indicated, and physiotherapists could be involved together with GPs as key primary care providers. Findings from this study must be interpreted with caution on account of the small, non-representative sample of participants surveyed.

\section{KEY POINTS}

1. On average, half of all quality indicators for osteoarthritis are being met in New Zealand.

2. Lowest achievement rates for osteoarthritis are for weight reduction and daily activity aids assessment.

3. There is no clear clinical pathway for osteoarthritis.

4. Physiotherapists could work together with GPs as key healthcare providers for osteoarthritis treatment.

\section{ACKNOWLEDGEMENTS}

The authors gratefully acknowledge funding from Arthritis New Zealand, in the form of a summer scholarship, which supported this research. 


\section{DISCLOSURES}

This study was supported by a grant from Arthritis New Zealand. The authors declare no conflicts of interest.

\section{PERMISSIONS}

Ethical approval for this study was granted by the Auckland University of Technology Ethics Committee (reference number 16/407).

\section{ADDRESS FOR CORRESPONDENCE}

Dr Daniel O'Brien, Senior Lecturer, Physiotherapy Department, School of Clinical Sciences, Auckland University of Technology, Private Bag 92006, Auckland, New Zealand. Tel: +64 9921 9999 ext 8707. Email: daniel.obrien@aut.ac.nz

\section{REFERENCES}

Access Economics. (2018). The economic cost of arthritis in New Zealand in 2018: Arthritis New Zealand. Retrieved from https://www.arthritis. org.nz/wp-content/uploads/2018/09/Economic-cost-of-Arthritis-in-NewZealand-2018.pdf

Baldwin, J., Briggs, A. M., Bagg, W., \& Larmer, P. J. (2017). An osteoarthritis model of care should be a national priority for New Zealand. New Zealand Medical Journal, 130(1467), 78-86.

Bliddal, H., Leeds, A. R., \& Christensen, R. (2014). Osteoarthritis, obesity and weight loss: Evidence, hypotheses and horizons - a scoping review. Obesity Reviews, 15(7), 578-586. https://doi.org/10.1111/obr.12173

Brand, C., Harrison, C., Tropea, J., Hinman, R. S., Britt, H., \& Bennell, K. (2014). Management of osteoarthritis in general practice in Australia. Arthritis Care \& Research, 66(4), 551-558. https://doi.org/10.1002/ acr.22197

Brosseau, L., Wells, G. A., Pugh, A. G., Smith, C. A., Rahman, P., Àlvarez Gallardo, I. C., ... Longchamp, G. (2016). Ottawa panel evidence-based clinical practice guidelines for therapeutic exercise in the management of hip osteoarthritis. Clinical Rehabilitation, 30(10), 935-946. https://doi. org/10.1177/0269215515606198

Brosseau, L., Wells, G. A., Tugwell, P., Egan, M., Dubouloz, C.-J., Casimiro, L., ... Ottawa Panel. (2011). Ottawa panel evidence-based clinical practice guidelines for the management of osteoarthritis in adults who are obese or overweight. Physical Therapy, 91(6), 843-861. https://doi.org/10.2522/ ptj.20100104

Carmona-Terés, V., Moix-Queraltó, J., Pujol-Ribera, E., Lumillo-Gutiérrez, I., Mas, X., Batlle-Gualda, E., ... Berenguera, A. (2017). Understanding knee osteoarthritis from the patients' perspective: A qualitative study. BMC Musculoskeletal Disorders, 18(1), 225. https://doi.org/10.1186/s12891017-1584-3

Chevalier, X., Marre, J. P., de Butler, J., \& Hercek, A. (2004). Questionnaire survey of management and prescription of general practitioners in knee osteoarthritis: A comparison with 2000 EULAR recommendations. Clinical and Experimental Rheumatology, 22(2), 205-212.

Cross, M., Smith, E., Hoy, D., Nolte, S., Ackerman, I., Fransen, M., ... March, L. (2014). The global burden of hip and knee osteoarthritis: Estimates from the global burden of disease 2010 study. Annals of the Rheumatic Diseases, 73(7), 1323-1330. https://doi.org/10.1136/ annrheumdis-2013-204763

Department of Veterans Affairs \& Department of Defense. (2014). VA/DoD clinical practice guideline for the non-surgical management of hip \& knee osteoarthritis. Retrieved from http://www.healthquality.va.gov/guidelines/ CD/OANADoDOACPGFINAL090214.pdf

Grønhaug, G., Hagfors, J., Borch, I., Østerås, N., \& Hagen, K. B. (2015). Perceived quality of health care services among people with osteoarthritis - results from a nationwide survey. Patient Preference and Adherence, 9 1255-1261. https://doi.org/10.2147/PPA.S82441
Grønhaug, G., Østerås, N., \& Hagen, K. B. (2014). Quality of hip and knee osteoarthritis management in primary health care in a Norwegian county: A cross-sectional survey. BMC Health Services Research, 14, 598. https:// doi.org/10.1186/s12913-014-0598-x

Hall, M., Migay, A.-M., Persad, T., Smith, J., Yoshida, K., Kennedy, D., \& Pagura, S. (2008). Individuals' experience of living with osteoarthritis of the knee and perceptions of total knee arthroplasty. Physiotherapy Theory and Practice, 24(3), 167-181. https://doi.org/10.1080/09593980701588326

Hermans, J., Koopmanschap, M. A., Bierma-Zeinstra, S. M. A., van Linge, J. H., Verhaar, J. A. N., Reijman, M., \& Burdorf, A. (2012). Productivity costs and medical costs among working patients with knee osteoarthritis. Arthritis Care \& Research, 64(6), 853-861. https://doi.org/10.1002/ acr.21617

Hochberg, M. C., Altman, R. D., April, K. T., Benkhalti, M., Guyatt, G. McGowan, J., ... American College of Rheumatology. (2012). American College of Rheumatology 2012 recommendations for the use of nonpharmacologic and pharmacologic therapies in osteoarthritis of the hand, hip, and knee. Arthritis Care \& Research, 64(4), 465-474.

Hooper, G. (2016). Access to joint replacement: Have we got it right? New Zealand Medical Journal, 129(1442), 6-7. Retrieved from https://www. nzma.org.nz/journal/read-the-journal/all-issues/2010-2019/2016/vol-129no-1442-23-september-2016/7012

Hooper, G., Lee, A., Rothwell, A., \& Frampton, C. (2014). Current trends and projections in the utilisation rates of hip and knee replacement in New Zealand from 2001 to 2026. The New Zealand Medical Journal, 127(1401), 82-93. Retrieved from https://www.nzma.org.nz/journal/readthe-journal/all-issues/2010-2019/2014/vol-127-no-1401/6276.

Hunter, D. J. (2011). Lower extremity osteoarthritis management needs a paradigm shift. British Journal of Sports Medicine, 45(4), 283-288. https:// doi.org/10.1136/bjsm.2010.081117

Hunter, D. J., \& Lo, G. H. (2009). The management of osteoarthritis: An overview and call to appropriate conservative treatment. Medical Clinics, 93(1), 127-143. https://doi.org/10.1016/j.mcna.2008.07.009

Jevsevar, D. S., Brown, G. A., Jones, D. L., Matzkin, E. G., Manner, P. A. Mooar, P., ... American Academy of Orthopaedic Surgeons. (2013). The American Academy of Orthopaedic Surgeons evidence-based guideline on: Treatment of osteoarthritis of the knee, 2nd edition. Journal of Bone and Joint Surgery (American), 95(20), 1885-1886. https://doi. org/10.2106/00004623-201310160-00010

Jolly, J., Bassett, S. F., O’Brien, D., Parkinson, C., \& Larmer, P. J. (2017). An exploration of the sequence and nature of treatment options available to people living with osteoarthritis of the hip and/or knee within a New Zealand context. New Zealand Journal of Physiotherapy, 45(2), 90-95. https://doi.org/10.15619/NZJP/45.2.05

Loew, L., Brosseau, L., Wells, G. A., Tugwell, P., Kenny, G. P., Reid, R., .. Ottawa Panel. (2012). Ottawa panel evidence-based clinical practice guidelines for aerobic walking programs in the management of osteoarthritis. Archives of Physical Medicine and Rehabilitation, 93(7), 1269-1285. https://doi.org/10.1016/j.apmr.2012.01.024

Ministry of Education. (2017). Profile \& trends 2016: Tertiary education outcomes and qualification completions. Wellington, New Zealand: Ministry of Education. Retrieved from https://www.educationcounts.govt. nz/_data/assets/pdf_file/0017/182303/2016-pt-outcomes-completionspartb2.pdf

Ministry of Health. (2010). Ethnic codes tables. New Zealand. https://www. health.govt.nz/nz-health-statistics/data-references/code-tables/commoncode-tables/ethnicity-code-tables

Ministry of Health. (2019). Annual update of key results 2017/18: New Zealand health survey. Wellington, New Zealand: Ministry of Health. https://minhealthnz.shinyapps.io/nz-health-survey-2017-18-annual-dataexplorer/_w_0811ceee/\#!/home

National Institute for Health and Care Excellence. (2015). Osteoarthritis quality standard. Retrieved from: https://www.nice.org.uk/guidance/qs87/ resources/osteoarthritis-pdf-2098913613253 
Østerås, N, Jordan, K. P., Clausen, B., Cordeiro, C., Dziedzic, K., Edwards, J., ... Hagen, K. B. (2015). Self-reported quality care for knee osteoarthritis: Comparisons across Denmark, Norway, Portugal and the UK. Rheumatic \& Musculoskeletal Diseases Open, 1(1), e000136. https://doi.org/10.1136/ rmdopen-2015-000136

Østerås, N., Garratt, A., Grotle, M., Natvig, B., Kjeken, I., Kvien, T. K., \& Hagen, K. B. (2013a). Patient-reported quality of care for osteoarthritis: Development and testing of the OsteoArthritis Quality Indicator questionnaire. Arthritis Care \& Research, 65(7), 1043-1051. https://doi. org/10.1002/acr.21976

Østerås, N., Garratt, A., Grotle, M., Natvig, B., Kjeken, I., Kvien, T. K., \& Hagen, K. B. (2013b). Patient-reported quality of care for osteoarthritis: Development and testing of the OsteoArthritis Quality Indicator questionnaire. Arthritis Care \& Research, 65(7), 1043-1051. https://doi. org/10.1002/acr.21976

Poitras, S., Rossignol, M., Avouac, J., Avouac, B., Cedraschi, C., Nordin M., ... Hilliquin, P. (2010). Management recommendations for knee osteoarthritis: How usable are they? Joint, Bone, Spine, 77(5), 458-465. https://doi.org/10.1016/j.jbspin.2010.08.001

Rillo, O., Riera, H., Acosta, C., Liendo, V., Bolaños, J., Monterola, L., .. Quintero, M. (2016). PANLAR consensus recommendations for the management in osteoarthritis of hand, hip, and knee. Journal of Clinical Rheumatology, 22(7), 345-354. https://doi.org/10.1097/ RHU.0000000000000449
Sauro, J., \& Lewis, J. R. (2005). Estimating completion rates from small samples using binomial confidence intervals: Comparisons and recommendations. Proceedings of the Human Factors and Ergonomics Society 49 ${ }^{\text {th }}$ Annual Meeting, 49(24), 2100-2103. https://doi. org/10.1177/154193120504902407

Sport New Zealand. (2015). Sport and active recreation in the lives of New Zealand adults: 2013/2014 active New Zealand survey results. Wellington, New Zealand. Retrieved from https://www.srknowledge.org.nz/wpcontent/uploads/2015/03/Active-NZ-Survey-WEB-FINAL1.pdf

Statistics New Zealand. (2013). Ethnicity New Zealand standard classification (No. V1.0). Retrieved from http://archive.stats.govt.nz/methods/ classifications-and-standards/classification-related-stats-standards.aspx

Zhang, W., Moskowitz, R. W., Nuki, G., Abramson, S., Altman, R. D., Arden, N., ... Tugwell, P. (2008). OARSI recommendations for the management of hip and knee osteoarthritis, Part II: OARSI evidence-based, expert consensus guidelines. Osteoarthritis and Cartilage, 16(2), 137-162. https:// doi.org/10.1016/j.joca.2007.12.013 


\section{Appendix A}

\section{QUESTIONNAIRE}

\section{Consent to participate in the survey}

1. I wish to take part in this study, I have read the participant information sheet on the previous page and have been given adequate time to make this decision.

\section{Demographic data}

2. What was your age in years at your last birthday?

3. What is your gender?

$\square$ Male

\section{$\square$ Female}

4. What is your ethnicity? (Please select all that apply)

New Zealand European

Māori

Pacific Islander

Asian

Indian

Middle Eastern

Latin American African

$\square$ Other (please specify)

5. What is your current occupational status?

Working full time

Working part time

$\square$ Unemployed

Retired

Disability beneficiary

$\square$ Other (please specify)

6. What is the highest level of school you have completed or the highest degree you have received?

$\square$ None

$\square$ Primary

$\square$ Secondary

$\square$ Tertiary

7. In a typical week, how many times do you engage in physical activity?

$\square$ Never

Less than once a week

$\square$ Once a week

$\square$ 2-3 times per week

$\square$ Almost every day

8. Other health problems: Has your doctor told you that you have any of the following? (Tick all those that apply to you)

$\square$ Other rheumatic diseases

$\square$ Other chronic non-rheumatic diseases

$\square$ No other rheumatic or chronic diseases

9. Please list the medications that you are currently taking for your osteoarthritis.

10. Please list any dietary supplements that you are currently taking for your osteoarthritis.

\section{Disease characteristics}

11. Which of your joints are affected by osteoarthritis?
$\square$ One hip joint
$\square$ Both hips joint
$\square$ One knee joint
$\square$ Both knee joints

12. How long have your experienced symptoms from osteoarthritis?

13. How long ago were you diagnosed with osteoarthritis by your GP?

14. Have you suffered from joint pain or stiffness in the last month?

$\square$ Yes $\square$ No

15. Please rate your pain in the last week on a scale from 0 to $10(0=$ no pain to $10=$ unbearable pain $)$.

\section{Number of healthcare visits in the past year}

16. In the past year, how many times have you consulted with your GP?

17. In the past year, how many times have you consulted with a medical specialist, e.g. rheumatologist?

18. In the past year, how many times have you consulted with an orthopaedic surgeon?

19. In the past year, how many times have you consulted with a physiotherapist?

20. In the past year, how many times have you consulted with an alternative health practitioner?

21. In the past year, how many times have you consulted with a health educator or peer support group?

22. Please list any other healthcare practitioners that you may have consulted in the past year, as well as the number of times you consulted with them.

\section{Information}

There are several different treatment alternatives for osteoarthritis. We would like to know what treatment, information or advice that you have been given for your osteoarthritis. For each question, please select one of the boxes provided. 
23. Have you been given information about how the disease usually develops over time?

\section{$\square$ Yes $\square$ No \\ $\square$ Don't remember}

24. Have you been given information about different treatment alternatives?

$\square$ Yes $\square$ No

$\square$ Don't remember

25. Have you been given information about how you can live with the disease?

$\square$ Yes $\square$ No

$\square$ Don't remember

26. Have you been given information about how you can change your lifestyle?

$\square$ Yes $\square$ No

Don't remember

27. Have you been given information about the importance of physical activity and exercise?

\section{$\square$ Yes $\square$ No}

$\square$ Don't remember

28. Have you been referred to someone who can advise you about physical activity and exercise? (e.g. a physiotherapist)

$\square$ Yes $\square$ No

$\square$ Don't remember

\section{Weight}

29. If you are overweight, have you been advised to lose weight?

$\square$ Yes $\square$ No

$\square$ Not overweight

30. If you are overweight, have you been referred to someone who can help you to lose weight?

$\square$ Yes $\square$ No

$\square$ Not overweight

Activities of daily living and mobility

31. If you have had problems related to daily activities, have these problems been assessed by health personnel in the past year?

\section{$\square$ Yes $\square$ No \\ $\square$ No such problems}

32. If you have problems with walking, has your need for a walking aid been assessed? (e.g. stick, crutch or walker)

\section{$\square$ Yes $\square$ No}

No such problems

33. If you have problems related to other daily activities, has your need for different appliances and aids been assessed? (e.g. splints, assistive technology for cooking or personal hygiene, or a special chair) $\square$ Yes $\square$ No

$\square$ No such problems

Pain and medication

34. If you have pain, has it been assessed in the past year?

$\square$ Yes $\square$ No

$\square$ No pain/discomfort

35. If you have pain, was Paracetamol or Panadol the first medicine that was recommended for your osteoarthritic pain?

$\square$ Yes $\square$ No

$\square$ No pain/discomfort

36. If you have prolonged severe pain which is not relieved sufficiently by paracetamol, have you been offered stronger pain killers? (e.g. coproxamol, co-dydramol, tramadol, cocodamol, dihydrocodeine or codeine).

$\square$ Yes $\square$ No

$\square$ No pain/discomfort

37. If you are taking anti-inflammatory drugs, have you been given information about the effects and possible side effects of this medicine? (e.g. Ibuprofen, Nurofen, Brufen, Diclofenac, Voltarol, Naproxen, Naprosyn or Celebrex).

$\square$ Yes $\square$ No

$\square$ No pain/discomfort

38. If you have experienced an acute deterioration of your symptoms, has a corticosteroid injection been considered?

$\square$ Yes $\square$ No

No pain/discomfort

\section{Surgery}

39. If you are severely troubled by your osteoarthritis, and exercise and medicine have not helped, have you been referred and assessed for an operation? (e.g. joint replacement)

$\square$ Yes $\square$ No

$\square$ I am not severely troubled by my osteoarthritis

40. If you answered yes to the question above, have you had surgery as a result of your osteoarthritis?

$\square$ Yes $\square$ No

$\square$ If yes, please specify. If no, do you anticipate that you will have surgery for your osteoarthritis?

\section{The order in which you sought treatment}

41. Name the healthcare providers and list them in the order in which you have sought help from them for your osteoarthritis. (e.g. if your GP was the first healthcare provider you sought help for your OA, then you write 1. GP. If you went to the pharmacist next independent of the GP (not to collect your prescription from the GP), then they are 2. Pharmacist. If the third source of help was a health food shop, then they are 3. Health food shop. 